Article

\title{
Estimating Floodplain Vegetative Roughness Using Drone-Based Laser Scanning and Structure from Motion Photogrammetry
}

\author{
Elizabeth M. Prior ${ }^{1, *(\mathbb{D}) \text {, Charles A. Aquilina }{ }^{1,2}{ }^{\text {, Jonathan A. Czuba }}{ }^{1} \mathbb{D} \text {, Thomas J. Pingel }}{ }^{3} \mathbb{D}$ \\ and W. Cully Hession ${ }^{1}$ \\ 1 Department of Biological Systems Engineering, Virginia Tech, Blacksburg, VA 24061, USA; \\ Charles.Aquilina@kleinschmidtgroup.com (C.A.A.); jczuba@vt.edu (J.A.C.); chession@vt.edu (W.C.H.) \\ 2 Kleinschmidt Associates, Strasburg, PA 17579, USA \\ 3 Department of Geography, Virginia Tech, Blacksburg, VA 24061, USA; tpingel@vt.edu \\ * Correspondence: eprior@vt.edu
}

Citation: Prior, E.M.; Aquilina, C.A.; Czuba, J.A.; Pingel, T.J.; Hession, W.C. Estimating Floodplain Vegetative

Roughness Using Drone-Based Laser Scanning and Structure from Motion Photogrammetry. Remote Sens. 2021, 13, 2616. https://doi.org/10.3390/ rs13132616

Academic Editor: Mateo Gašparović

Received: 31 May 2021

Accepted: 30 June 2021

Published: 3 July 2021

Publisher's Note: MDPI stays neutral with regard to jurisdictional claims in published maps and institutional affiliations.

Copyright: (c) 2021 by the authors. Licensee MDPI, Basel, Switzerland. This article is an open access article distributed under the terms and conditions of the Creative Commons Attribution (CC BY) license (https:// creativecommons.org/licenses/by/ $4.0 /)$.

\begin{abstract}
Vegetation heights derived from drone laser scanning (DLS), and structure from motion (SfM) photogrammetry at the Virginia Tech StREAM Lab were utilized to determine hydraulic roughness (Manning's roughness coefficients). We determined hydraulic roughness at three spatial scales: reach, patch, and pixel. For the reach scale, one roughness value was set for the channel, and one value for the entire floodplain. For the patch scale, vegetation heights were used to classify the floodplain into grass, scrub, and small and large trees, with a single roughness value for each. The roughness values for the reach and patch methods were calibrated using a two-dimensional (2D) hydrodynamic model (HEC-RAS) and data from in situ velocity sensors. For the pixel method, we applied empirical equations that directly estimated roughness from vegetation height for each pixel of the raster (no calibration necessary). Model simulations incorporating these roughness datasets in 2D HEC-RAS were validated against water surface elevations (WSE) from seventeen groundwater wells for seven high-flow events during the Fall of 2018 and 2019, and compared to marked flood extents. The reach method tended to overestimate while the pixel method tended to underestimate the flood extent. There were no visual differences between DLS and SfM within the pixel and patch methods when comparing flood extents. All model simulations were not significantly different with respect to the well WSEs $(p>0.05)$. The pixel methods had the lowest WSE RMSEs (SfM: $0.136 \mathrm{~m}$, DLS: $0.124 \mathrm{~m}$ ). The other methods had RMSE values $0.01-0.02 \mathrm{~m}$ larger than the DLS pixel method. Models with DLS data also had lower WSE RMSEs by $0.01 \mathrm{~m}$ when compared to models utilizing SfM. This difference might not justify the increased cost of a DLS setup over SfM ( 150,000 vs. 2000 USD for this study), though our use of the DLS DEM to determine SfM vegetation heights might explain this minimal difference. We expect a poorer performance of the SfM-derived vegetation heights/roughness values if we were using a SfM DEM, although further work is needed. These results will help improve hydrodynamic modeling efforts, which are becoming increasingly important for management and planning in response to climate change, specifically in regions were high flow events are increasing.
\end{abstract}

Keywords: lidar; structure from motion; vegetative roughness; drones; unoccupied aerial system; floodplains; flooding; hydrodynamic modeling; HEC-RAS; flooding

\section{Introduction}

Riverscapes are dynamic, linear riverine systems characterized by high connectivity and spatial complexity [1,2]. Riverscapes provide crucial economic and societal services, but are also prone to flood hazards [3]. Changes in the hydrologic cycle due to climate change has resulted in increased heavy precipitation events and more extreme high-flow events in the Eastern United States (US) [4]. The ability to accurately model floods will be 
of utmost importance for management activities in response to the challenges regarding climate change [5].

Remote sensing techniques have been increasingly utilized to measure parameters related to ecological and hydrological function of riverscapes due to decreased costs and increased resolution [6]. Advancements in the technology and policy regarding unoccupied aerial vehicles (UAV), or drones, have made these systems useful to researchers in smallto medium-sized study areas $\left(<1-10 \mathrm{~km}^{2}\right)$ [7]. UAVs are operationally more flexible and less expensive than aerial surveys (planes) and, because they can fly at lower altitudes, the surveys produce data with higher resolution [8,9]. Of particular note for this paper, there has been interest in using UAV data for hydraulic roughness estimates for use in hydrodynamic modeling $[10,11]$.

Roughness, which represents the resistance to flow in channels and floodplains [12], is an important hydraulic characteristic that influences water surface elevation (WSE) and velocity [13]. One of the most widely used roughness parameters is Manning's roughness $(n)$, which is utilized in Manning's empirical equation (Equation (1)) for determining average velocity and discharge in open channels [14],

$$
Q=V A=\frac{1}{n} A R^{\frac{2}{3}} S^{\frac{1}{2}}
$$

where $Q$ is discharge $\left(\mathrm{m}^{3} / \mathrm{s}\right), V$ is velocity $(\mathrm{m} / \mathrm{s}), A$ is cross sectional area $\left(\mathrm{m}^{2}\right), R$ is hydraulic radius ( $\mathrm{m}$; calculated as $A$ divided by the length of the wetted perimeter), and $S$ is slope $(\mathrm{m} / \mathrm{m})$.

Manning's roughness is one of the most sensitive variables in the equation, yet the hardest to estimate [15]. Roughness has been estimated using look-up tables based on descriptions of the channel, floodplain, and vegetation type [16], or by comparing with photos of sites with previously calculated roughness values [17]. Other methods distribute total roughness among important components: particle size, surface irregularities, shape and size of the channel cross section, obstructions, vegetation, and channel planform [18]. All of these methods are highly subjective and, therefore, increase uncertainties associated with determining $n$ [19]. While these techniques are still being used for basic estimates of roughness, new methods have been developed to determine $n$ in more quantitative, objective ways [20,21].

Vegetative resistance is an important component of overall roughness, and recent studies have improved roughness estimates influenced by vegetation [19-22]. Restoration of riparian or streamside forests has been a focus of stream restoration initiatives. Many efforts have been made to quantify their effects on WSEs and velocities [13] because vegetation converts mean kinetic energy to turbulent kinetic energy, thus affecting drag and turbulence [23]. Studies involving theory-based equations and empirical equations determined from flume data have been developed for submerged and emergent floodplain vegetation [24-26]. These equations, dependent on plant characteristics and their spatial distribution, have been applied to map the spatial distribution of roughness across a floodplain [20]. Abu-Aly et al. [22] found that adding spatially distributed vegetation roughness metrics in a two dimensional (2D) hydrodynamic model resulted in a more accurate representation of the riverscape. When compared to a constant roughness model significant differences were found, including a decrease in mean velocity $(-17.5 \%)$, an increase in wetted area (8\%), and an increase in mean channel depth $(7.4 \%)$.

One method of calculating vegetative roughness is to utilize data from light detection and ranging (lidar), which is referred to as aerial laser scanning (ALS) when collect from an aircraft $[27,28]$. There have been many environmental applications of ALS, such as measuring canopy heights [27,29], terrain modeling [30], and measuring vegetative density [28,31]. The ability of ALS to collect data across large areas is useful for measuring physical parameters of riverscapes such as stream gradient, width, and sinuosity [32]. While vegetative density is an important field-derived variable for many roughness equations [20], lidar- 
derived vegetative density was not found to have sufficient correlation to field-derived vegetative density [31], but further investigation into this parameter is warranted.

A method outlined by Mason et al. [27] used ALS-derived vegetation height to determine $n$ in floodplains. However, ALS point densities are typically limited to 10 points $/ \mathrm{m}^{2}$, making it difficult to detect small changes in the vegetation and terrain [8]. Another lidar platform, drone laser scanning (DLS), is a novel method to measure riverscapes. Resop et al. [8] compared ALS to DLS and found a large increase in the amount of points classified as vegetation, from $2 \%$ to $12 \%$. They also found that DLS was more accurate in measuring heights, widths, and lengths of objects in the landscape such as bridges and fences. Because of the increase in accuracy and the detection of more points, including vegetation points, they concluded that DLS better captured the spatial heterogeneity of both the terrain and vegetation [8].

DLS is uniquely positioned to measure vegetative metrics as it allows for increased temporal (daily, monthly, seasonal flights), and spatial resolutions (more than $400 \mathrm{pts} / \mathrm{m}^{2}$ at 30-m flight elevation for the unit used in this study). Since UAVs fly at low altitudes, the data resolution is well suited for hard-to-scan areas along riverscapes such as steep streambanks and areas of dense vegetation [8]. The increase in resolution is also important for low-lying vegetation and surface roughness, which are not as well detected by ALS or other remote sensing methods [8]. DLS has been shown to have lower error than ALS at measuring heights of a variety of vegetation types, which should lead to improved roughness estimates [7,33].

In many studies, a UAV is paired with a camera as it is a more affordable option compared to lidar systems [9,33-36]. Structure from motion (SfM) photogrammetry can then be utilized to overlap the resulting aerial photos and create a point cloud of a landscape [35]. Past riverscape studies involving UAVs have used SfM photogrammetry techniques to determine characteristics of riverscapes, such as mapping vegetation distribution [37], detecting large woody debris [38], and monitoring stream restoration efforts [39]. Accuracy of SfM point clouds can be improved with the use of ground control points (GCPs), which are surveyed points that can be seen in the aerial images [40,41]. Generally, ten randomly dispersed GCPs are recommended per flight [38]. SfM photogrammetry can barely penetrate a canopy resulting in almost no ground detection, depending on leaf area and canopy closure [34]. This can result in object height errors within the point clouds, especially in densely vegetated areas [35]. The possible products from SfM (e.g., digital elevation models (DEM) and canopy height models (CHM)) are prone to errors that can propagate through to estimates of roughness [40].

Past studies have used spatially variable roughness for 2D hydrodynamic modeling $[27,42,43]$, some with field-derived vegetation measurements such as drag coefficients [20]. Studies investigating vegetation roughness have utilized a variety of 2D hydrodynamic models, such as Telemack 2D [42], MIKEFLOOD [44], RIVER2D [43,45] and SRH-2D [22]. In this study, we utilized 2D HEC-RAS (Hydrologic Engineering CenterRiver Analysis System), a 2D hydrodynamic model developed by the US Army Corps of Engineers (USACE) [46]. 2D HEC-RAS utilizes the Saint Venant equations to simulate unsteady flow [46] and can take advantage of high-resolution remotely sensed datasets to create spatially variable outputs, such as WSEs, velocities, and flood extents [22].

The purpose of this study was to evaluate and compare 2D hydrodynamic model simulations of floods using different methods of estimating roughness based on DLS and SfM point clouds. We determined hydraulic roughness at three spatial scales: reach, patch, and pixel. For the reach scale, one roughness value was assigned for the channel and one roughness value for the floodplain. The patch method utilized the vegetation heights to classify the floodplain into grass, scrub, and small and large trees, and assigned a roughness value to each classification. The pixel method applied empirical equations depending on the vegetation height for each pixel of the raster [27]. Reach and patch scale roughness values were calibrated using 2D HEC-RAS and data from velocity sensors. These roughness estimates were then utilized in the 2D HEC-RAS hydrodynamic model [46]. Model 
simulations were validated against WSEs from seventeen groundwater wells at seven high-flow events during the Fall of 2018 and 2019 and compared to marked flood extents. This work leads to the better characterization of vegetative roughness on floodplains with the potential for more accurate hydrodynamic models.

\section{Materials and Methods}

\subsection{Study Area}

The Virginia Tech (VT) Stream Research, Education, and Management (StREAM) Lab is along a $1.5 \mathrm{~km}$ reach of Stroubles Creek downstream of the VT campus in Blacksburg, Virginia, USA (Figure 1) [47]. Stroubles Creek is a gravel-bedded stream, with headwaters located entirely within the Town of Blacksburg and the VT campus. The watershed upstream of the study area is $14.5 \mathrm{~km}^{2}$ and is $90 \%$ urban [48]. The Stroubles Creek watershed is highly urbanized and, therefore, experiences rapid flood events and erosion. Due to the aforementioned issues, Stroubles Creek has been on the U.S. Environmental Protection Agency's 303(d) list of impaired streams since 2003 [49].

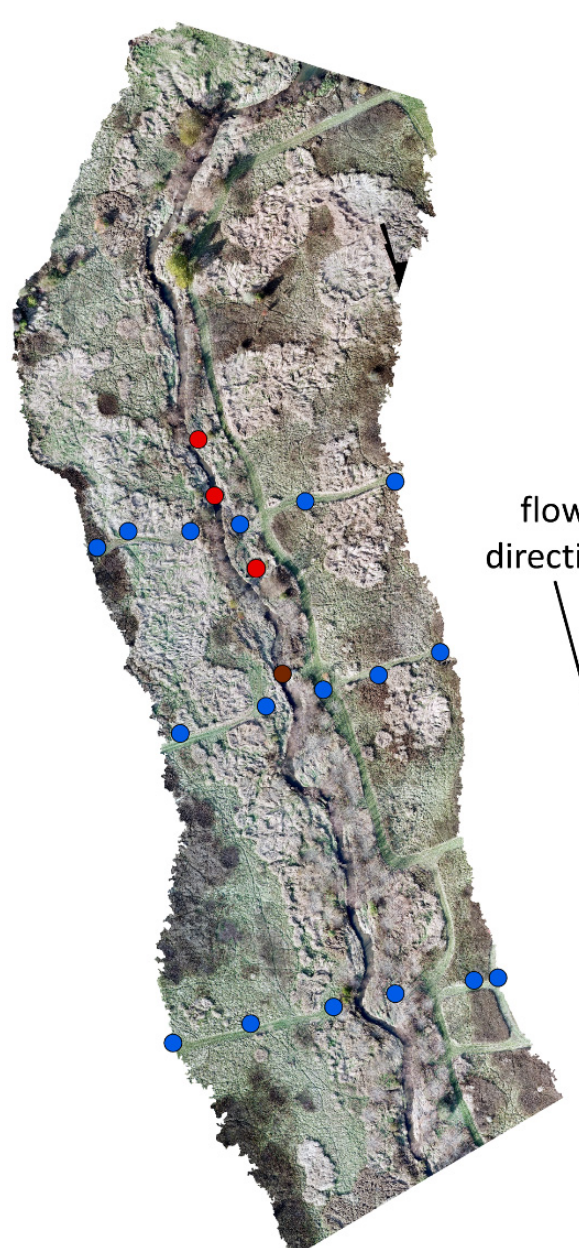

(a)

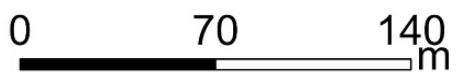

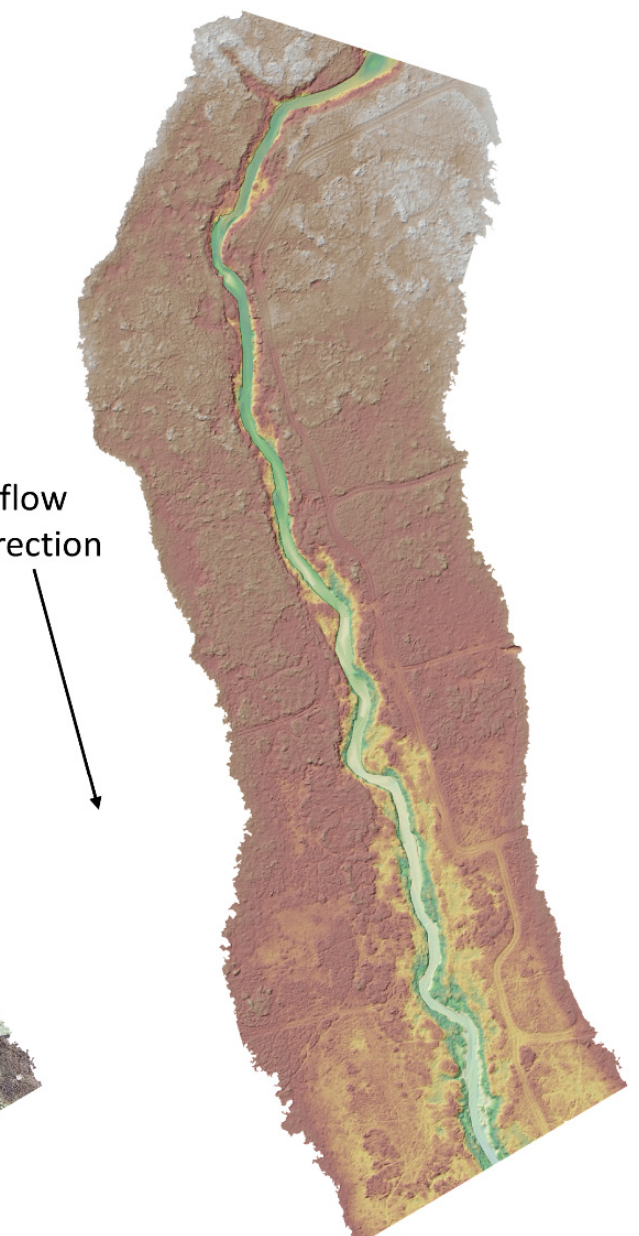

(b)

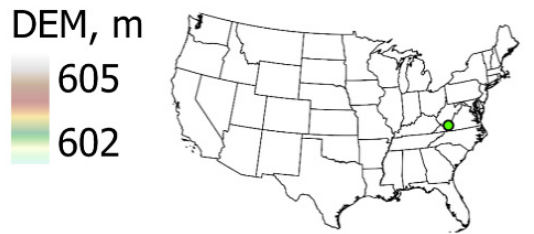

Figure 1. StREAM Lab map: (a) orthophoto with important in situ data collection locations denoted, (b) digital elevation model of StREAM Lab created from the DLS point cloud. 
During 2009 and 2010, $1.5 \mathrm{~km}$ of Stroubles Creek was restored at the StREAM Lab [50]. The section between the top of the orthophoto and Bridge 2 (Figure 1a) involved regraded vertical streambanks to a 3 to 1 slope and planting native riparian vegetation, while the section downstream of Bridge 2 utilized a natural channel design that included installing inset floodplains that transition to 3 to 1 slopes [50]. The restoration project increased floodplain connectivity and vegetative complexity [51]. Because of the increased floodplain connectivity and well-established vegetative cover from the restoration, we chose this section of the StREAM Lab to evaluate vegetative roughness in relation to flood modeling.

\subsection{Data Collection}

\subsubsection{Field Data}

At StREAM Lab, there is in situ monitoring to assess the long-term effects of the stream restoration completed in 2010. Within our specific study area, there is one monitoring bridge (Bridge 2; Figure 1a) where stage and water quality parameters are continuously measured (every $15 \mathrm{~min}$ ). There are seventeen wells with pressure transducers (HOBO, Onset Computer Corporation, Bourne, MA, USA) measuring water elevations every 15 min (Figure 1a). Water elevations from the wells were utilized at the peaks of the measured floods as determined by the stage sensor at Bridge 2 (Figure 2). Measured floods were selected during the Fall of 2018 and 2019. Sontek-IQ Plus uplooking acoustic Doppler velocity meters (Sontek - a Xylem brand, San Diego, CA, USA) were deployed upstream of Bridge 2 to measure velocity and WSE in the channel and on the floodplain (Figure 1a). The floodplain sensor was initially deployed at the downstream location, but was moved to the upstream location on the inset floodplain on 30 October 2019 to capture data at lower flows and to avoid backwater that was affecting the initial floodplain sensor location. The velocity sensors, placed in the thalweg, recorded an average velocity profile over a duration of $2 \mathrm{~min}$ and reported this average velocity profile every $5 \mathrm{~min}$. That is, the velocity data have a 5-min resolution and each "instantaneous" measurement is a 2-min average. Vertically averaged velocity (which is simulated in our 2D model) was estimated from our velocity profile data by fitting a logarithmic curve [52,53] to the profile obtained every $5 \mathrm{~min}$ and then determining the average velocity from the curve fit. This was done to account for unmeasured regions in the velocity profile (near the bed and at the water surface) to obtain the most representative average value [53]. Lastly, the extent of the flood that occurred on 11 October 2018 was flagged and surveyed to determine WSEs at the peak flow throughout the study area. These field data were used to calibrate (velocity sensors), validate (wells), and compare (flood extents) the roughness metrics derived from SfM and DLS techniques.

\subsubsection{DLS Data}

The UAV system utilized for lidar surveys was a Vapor35 (AeroVironment, Simi Valley, CA, USA) with a YellowScan Surveyor Core lidar unit (Monfeerier-sur-Lez, France). The lidar unit consists of a Velodyne VLP-16 laser scanner (Velodyne, San Jose, CA, USA) and a GNSS-inertial Trimble APPLANIX APX-15 (Trimble, Richmond Hill, ON, Canada). To plan and conduct Vapor35 flights, we used the wePilot1000 flight control system and the weGCS ground control system software (weControl SA, Courtelary, Switzerland). The lidar flights were flown at a $30 \mathrm{~m}$ altitude, with $20 \mathrm{~m}$ flight-line spacing, which was recommended by YellowScan staff for optimum point spacing and density. The lidar flight was conducted on 9 October 2018. 


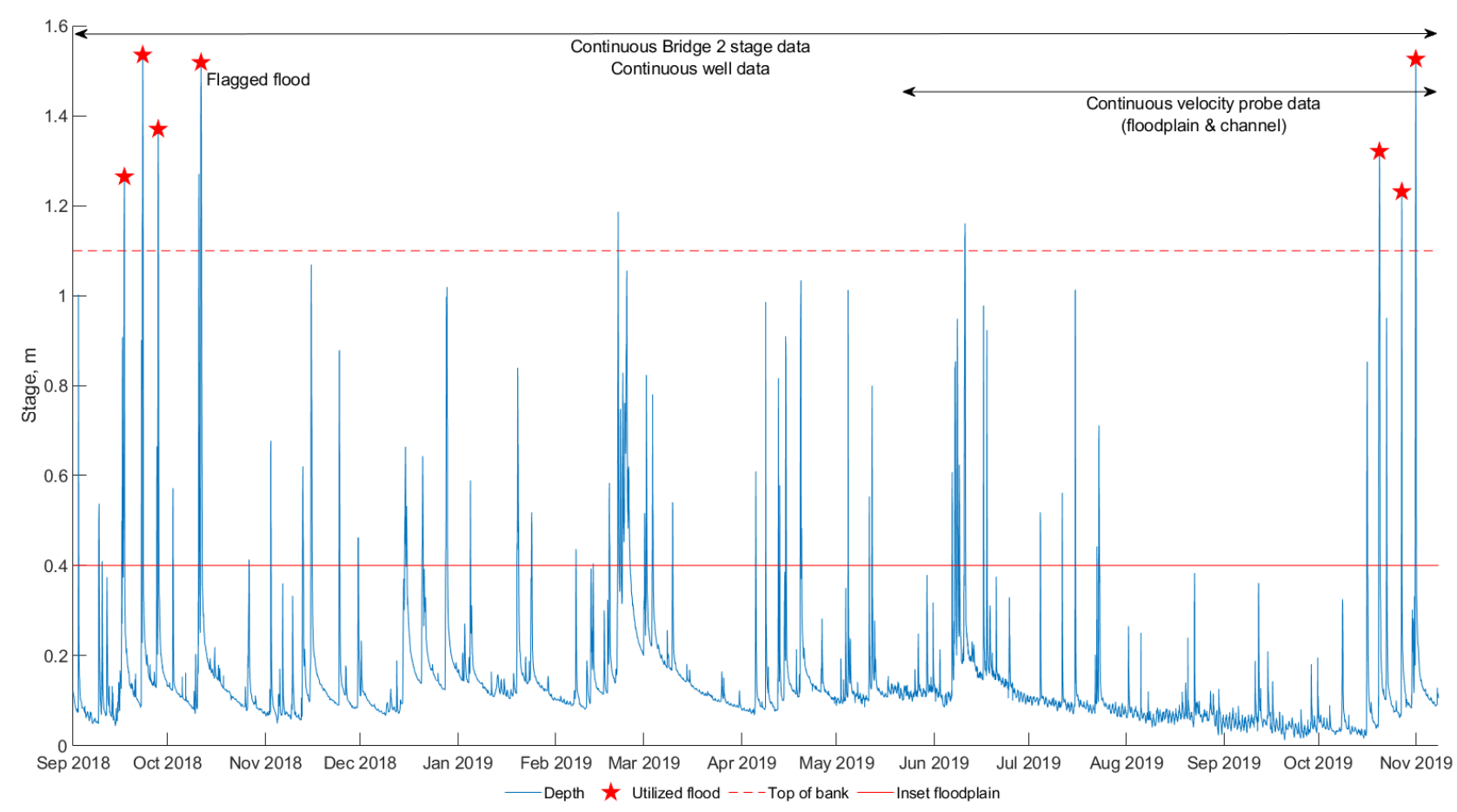

Figure 2. Stage hydrograph recorded at Bridge 2 of StREAM Lab with the seven utilized floods and the durations of sensor data collection.

The YellowScan system is ultralight $(2.1 \mathrm{~kg})$ which is the allowable payload limit for the Vapor35. The lidar system can record two returns per pulse and uses a wavelength of $905 \mathrm{~nm}$. The Velodyne VLP-16 and the APPLANIX unit allow for one button data acquisition. After the flight, data was corrected using a local CORS base station, and was outputted into a LAS file format in UTM zone 17N. Figure $3 \mathrm{~b}$ shows a subsection of lidar from our study site. Figure $3 \mathrm{c}$ shows subsections of the lidar to demonstrate the variable vegetation heights throughout the floodplains.

\subsubsection{SfM Data}

The UAV system utilized for collecting aerial imagery was a DJI Mavic Pro (DJI, Shenzen, China) with an included 4k camera. The camera specifications are "1/2.3" (CMOS), effective pixels: $12.35 \mathrm{M}$ (Total pixels: $12.71 \mathrm{M}$ ), according to the DJI website. The DJI Flight Mapper (AeroScientific, Adelaide, Australia) application was utilized to create flight maps in the study area, while the Litchi (VC Technology, London, UK) application was used to conduct the pre-programmed flights. Flights were conducted at midday to minimize shadow effects on the images and a total of nine GCPs were used. The study area was divided into three flight areas due to flight motor battery constraints, with the camera at nadir. Flights were flown at $36.5 \mathrm{~m}$ altitude with settings recommended by the DJI Flight Mapper application. A fourth flight was flown over the entire study area at $61 \mathrm{~m}$ altitude with the camera at 75 degrees. Flights flown at different angles and altitudes have been determined to create more accurate point clouds, as it creates a more comprehensive view of the landscape $[54,55]$. Images were taken every $2 \mathrm{~s}$ to ensure an $80 \%$ overlap to improve the accuracy of the point cloud. The photogrammetry flight was conducted on 11 June 2020, resulting in 3505 images.

The acquired images were post-processed using Agisoft Metashape (Agisoft Metashape, St. Petersburg, Russia) following a standard workflow: importing the UAV images, initial processing, importing the GCPs, and creating a dense point cloud. This process resulted in a point cloud in LAS file format in UTM Zone $17 \mathrm{~N}$. 


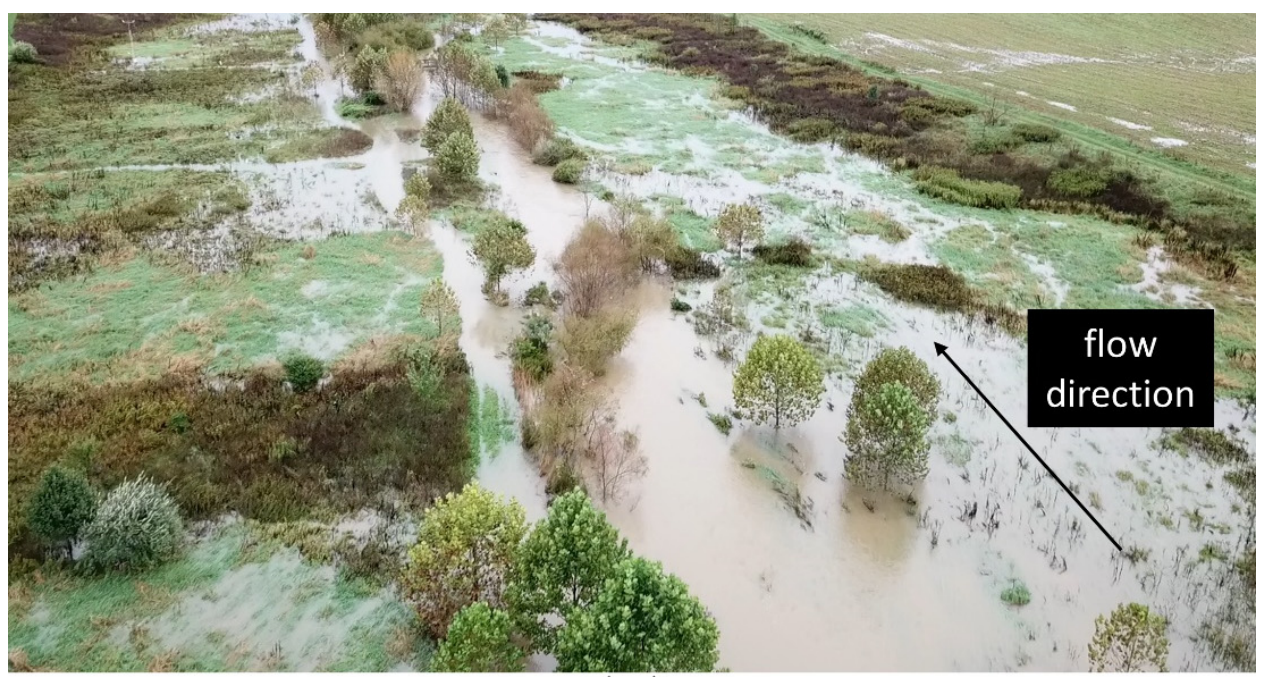

(a)

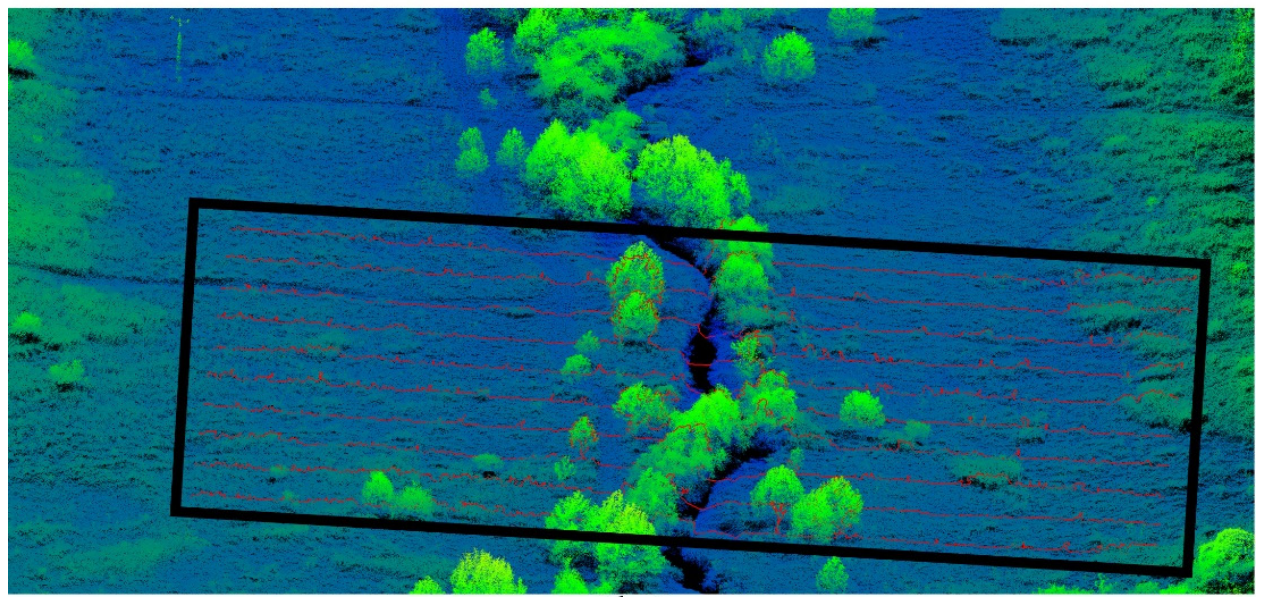

(b)

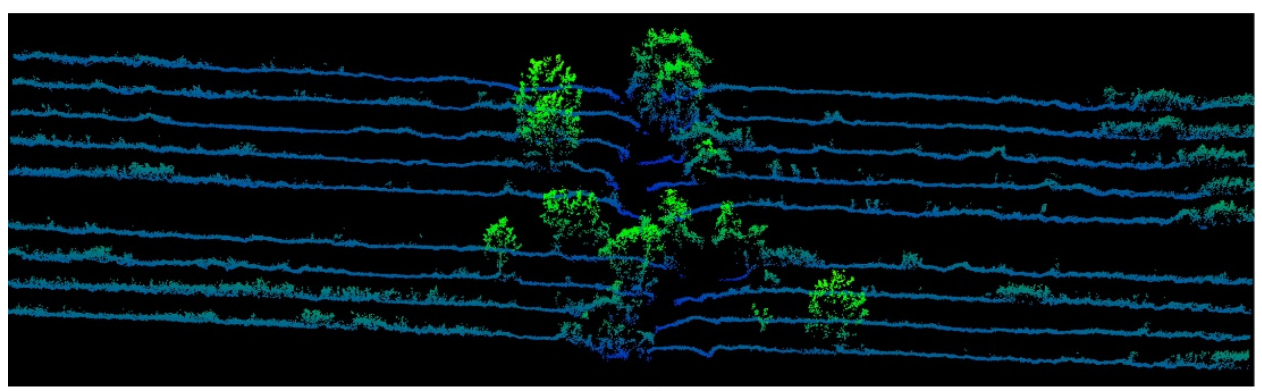

(c)

Figure 3. Visualization of StREAM Lab: (a) flood from Hurricane Michael on 11 October 2018, (b) DLS point cloud with the black rectangular box denoting where Figure $3 \mathrm{c}$ is located, (c) zoom in focusing on cross-sections taken from Figure $3 \mathrm{~b}$ highlighting the vegetation variation across the floodplain.

\subsubsection{Final Point Cloud Data}

Lidar and SfM point clouds were not adequate for producing channel bathymetry measurements, therefore we conducted a detailed survey of the below-water stream channel with a Trimble R12 GNSS System (Trimble, Sunnyvale, CA, USA) to fill in the data gaps. Gaps in the point cloud were present since near infrared light, which is used by our lidar unit, is absorbed by water. We did not use SfM to measure bathymetry due the need 
to correct for reflection, refraction and turbidity and since most of the stream is covered by the canopy. Bathymetry data were collected at the top and toe of banks and at least one point in the deepest part of channel cross sections at streamwise spacings of roughly one channel width apart. LAStools (rapidlasso $\mathrm{GmbH}$, Gilching, Germany) was used to classify the ground points of the point clouds using the default settings of the LASground tool. ArcGIS Pro (ESRI, Redlands, CA, USA) was used to manually classify points such as bridges and other human-made objects. All other above-ground points were considered vegetation, with a $0.1 \mathrm{~m}$ buffer to account for uncertainty between the ground and the low vegetation. This classification of vegetation points, height normalization using the ground points, and creation of a CHM were performed using the LASheight and LAS2dem tools in LAStools. The CHM pixel size was set to $0.1 \mathrm{~m}$ to take advantage of the high-resolution data of both point clouds. For our study, CHM represents vegetation heights and DEM represents bare earth elevation. The final point cloud density for lidar was approximately 262 points per $\mathrm{m}^{2}$ and 1480 points per $\mathrm{m}^{2}$ for SfM

\subsection{Roughness Raster Creation}

To create a raster data layer of vegetative roughness, three different roughness estimation techniques were implemented. For the first method, hereafter referred to as the "reach" method, we calibrated one roughness value for the entire channel and one value for the entire floodplain (including the inset floodplain). We used the in-channel velocity sensor to calibrate the channel roughness and the floodplain velocity sensor to calibrate the floodplain roughness.

For the second method, hereafter referred to as the "patch" method, we created a roughness raster layer for classes of floodplain vegetation. Utilizing the generated CHMs (Figure $4 \mathrm{~d}, \mathrm{e})$, vegetation height ranges were used to reclassify pixels into vegetative groups of grass $(0 \mathrm{~m}$ to $1 \mathrm{~m})$, scrub ( $1 \mathrm{~m}$ to $2.5 \mathrm{~m})$, small trees $(2.5 \mathrm{~m}$ to $5 \mathrm{~m})$, and large trees $(5 \mathrm{~m}$ to $20 \mathrm{~m}$ ) [16]. As in the previous method, these vegetation classes were then calibrated by changing the roughness parameters to best fit the velocity sensor data (Figure 4h,i).

The third method was a simplified version of an approach developed by Mason et al. [27], hereafter referred to as the "pixel" method. The pixel method uses simplified flume and theoretical relationships so that only vegetation heights are required to solve for DarcyWeisbach friction coefficients, $f$. The friction coefficients were then converted to $n$, using a relationship developed by Fathi-Maghadam and Kouwen [26]. This method assumes similar rigidity, shape, and momentum absorptivity of vegetative classes to avoid the need for extensive field work to determine individual plant properties [56].

Formulas have been developed to predict $f$ for short submerged vegetation less than $1 \mathrm{~m}$ (Equation (2)) [25,57] and emergent medium to tall vegetation (Equation (3)) [26],

$$
\begin{gathered}
\frac{1}{\sqrt{f}}=a+b \log \left(\frac{y_{n}}{k}\right) \\
f=4.06\left[\frac{V}{\sqrt{\frac{\varepsilon E}{\rho}}}\right]^{-0.46} \frac{y_{n}}{h}
\end{gathered}
$$

where $V$ is the flow velocity $(\mathrm{m} / \mathrm{s}), \rho$ is water density $\left(\mathrm{kg} / \mathrm{m}^{3}\right), y_{n}$ is the normal depth of water $(\mathrm{m}), h$ is the vegetation height $(\mathrm{m})$ (Figure $4 \mathrm{~d}, \mathrm{e}), \varepsilon E$ is a measure of tree elasticity $\left(\mathrm{N} / \mathrm{m}^{2}\right)$, and $k$ is the deflected grass vegetation height $(\mathrm{m})$. The variables $a$ and $b$ are related to the boundary shear stress. Since 2D HEC-RAS (version 5.07) cannot utilize stage dependent roughness, typical values were used for the depth $\left(y_{n}=1 \mathrm{~m}\right)$ and velocity ( $V=0.05 \mathrm{~m} / \mathrm{s}$ ) to determine $f$, similar to what was employed by Hopkinson et al. [56]. As in Mason et al. [27], we used elasticity values determined by Kouwen and FathiMoghadam [26]. The $\varepsilon E$ selected was white pine $(\varepsilon E=2.99)$, lying in the range of the trees in our study site. 


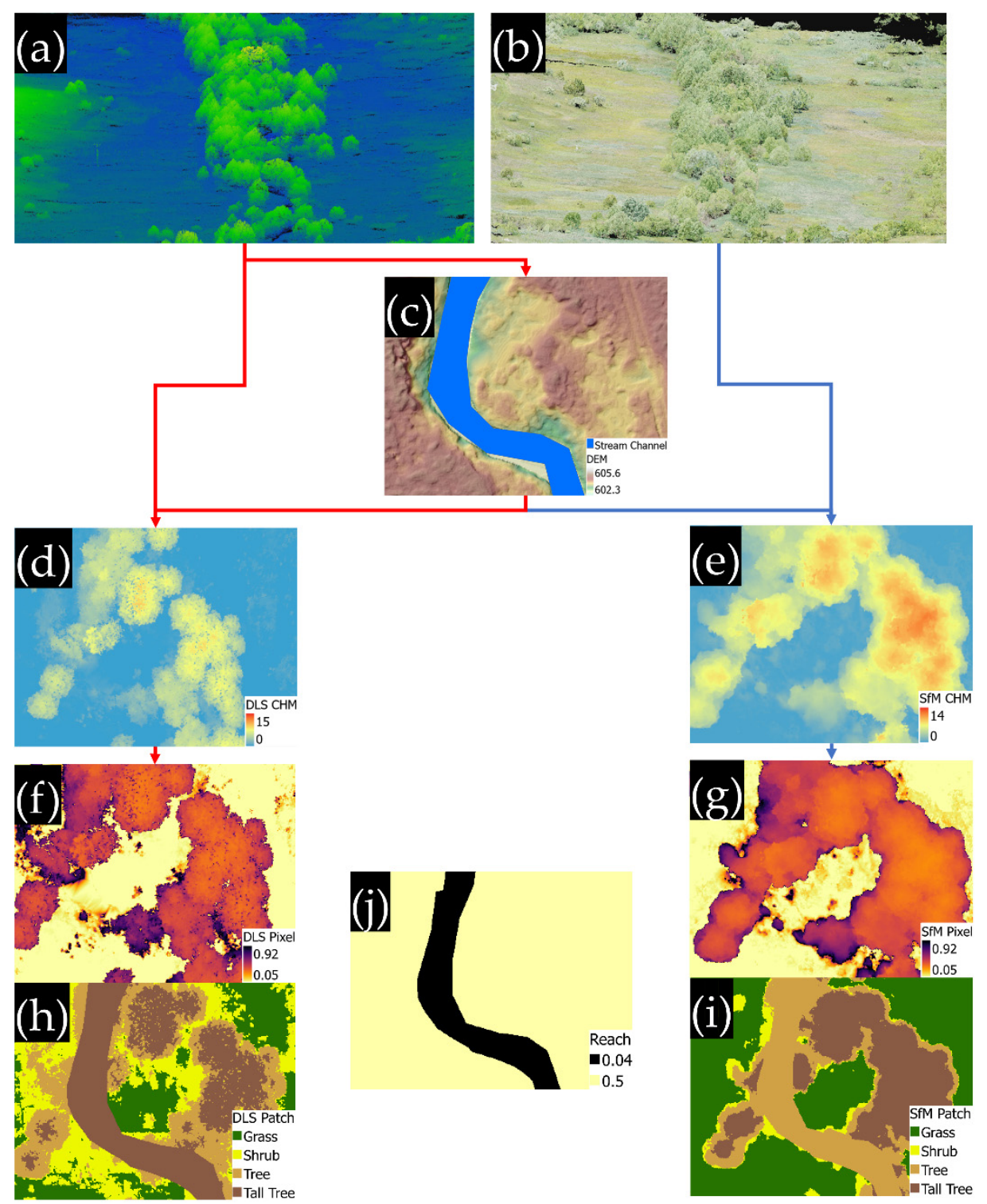

Figure 4. Data visualization workflow: (a) DLS point cloud of the study site, (b) SfM point cloud of the study site, (c) DEM derived from the DLS point cloud at a meander bend, (d) DLS CHM, (e) SfM $\mathrm{CHM}$, (f) roughness raster from the pixel method using DLS, $(\mathrm{g})$ roughness raster from the pixel method using SfM, (h) roughness raster from the patch method using DLS, (i) roughness raster from the patch method using SfM, (j) roughness raster from manually assigned floodplain and channel roughness values.

The final raster of $n$ was calculated from the friction coefficient (Equation (4)) [27]. Since this is a calculated roughness, it was not calibrated like the first two methods. Assuming that the hydraulic radius equals the normal depth, Manning's roughness was determined using a relationship developed by Fathi-Maghadam and Kouwen [26],

$$
n=\sqrt{\frac{f y_{n}^{1 / 3}}{8 g}}
$$

where $g\left(\mathrm{~m} / \mathrm{s}^{2}\right)$ is the gravitational acceleration constant.

The patch and pixel methods were repeated with the UAV SfM photogrammetry data (Figure $4 \mathrm{~g}$,i). To ensure spatial consistency, the SfM point cloud was aligned to the DLS point cloud using the align tool in CloudCompare (https:/ / www.danielgm.net/cc/, 
accessed on 15 August 2018). This was then put through a similar workflow as the DLS point cloud to create a CHM using the DLS DEM and vegetation points from the SfM dataset. This CHM (Figure 4e) was then used to produce raster roughness layers using the patch and pixel methods described above (Figure $4 \mathrm{~g}$,i). Since the datasets were similar, the calibrated DLS patch roughness values were used for SfM patch roughness values. To focus the study on vegetation roughness, the DLS DEM was used for all models to ensure that the roughness parameter was the only changing variable between each model.

\subsection{Hydrodynamic Modeling}

The data analyses and modeling process are illustrated in Figure 5. After data collection activities we created a 2D HEC-RAS model to simulate flooding at the study site using the three different Manning's roughness estimation methods, or five different roughness inputs because of DLS and SfM data. 2D hydrodynamic modeling was used to predict WSEs, flood extent, and flow velocities at several steady-state discharges. Inputs for 2D HEC-RAS included the DLS DEM, the slope at the downstream boundary, a flow area to create a mesh of calculation points created in the program, a series of flows at the upstream boundary condition, and a roughness raster. We generated a 2D mesh in HEC-RAS consisting of $1 \mathrm{~m}^{2}$ cells, each containing a calculation point. The grid mesh had break-lines in the channel and along the inset floodplain to align the mesh to the stream channel, so that water did not prematurely flow into the floodplain.

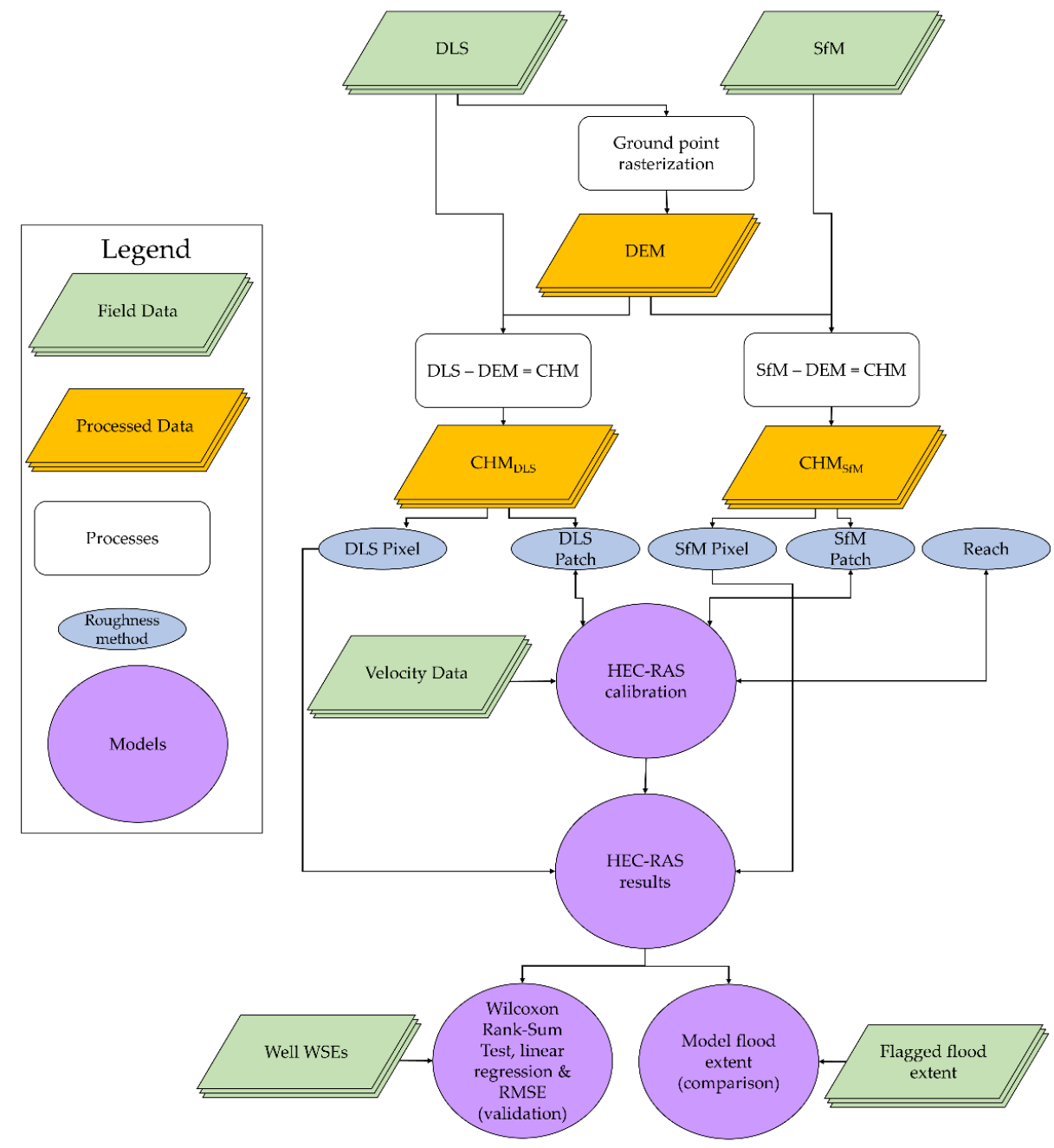

Figure 5. Workflow showing how remotely sensed data were manipulated for use in each roughness raster creation, as well as how models used each raster along with field data calibration (velocity data), validation (well WSEs), and comparison (flagged flood extent). 


\subsection{Model Validation}

To evaluate modeled results, we compared predicted versus measured well WSEs for the seven flood events using a Wilcoxon Rank-Sum Test resulting in $p$-values and linear regression, resulting in $r^{2}$ values. The null hypothesis tested was no significant difference between the well WSEs and the corresponding modeled WSEs. This method was used by Cobby et al. [42] in a similar study to validate constant and variable friction 2D hydrodynamic model outputs compared to synthetic aperture radar-derived flood extents.

To assess which model better predicted flooding, we compared measured WSE to the modeled WSE at each measured flood peak using the root mean square error (RMSE) (Equation (5)).

$$
R M S E=\sqrt{\frac{1}{N} \sum_{i=1}^{N}\left(x_{i}-\hat{x}_{i}\right)^{2}}
$$

where $\hat{x}_{i}$ is the modeled WSE and $x_{i}$ is the measured WSE. All statistics were done in R (version 4.0.3).

\section{Results}

Depth-average velocities and WSEs from the velocity sensors were used to visually calibrate the roughness values for the reach and patch methods (Figure 6). WSEs and velocities were extracted from the models at the locations of each velocity sensor. For the reach method, the final calibrated roughness values used for the channel and the floodplain were 0.04 and 0.5 , respectively. For the patch method, the final calibrated roughness values were grass $(n=0.05)$, scrub $(n=0.07)$, small tree $(n=0.16)$, and large tree $(n=0.20)$. At an elevation of approximately $604.3 \mathrm{~m}$, flow began to overtop the banks and inundate the floodplain. For the in-channel velocity sensor, all models were relatively consistent among each other and generally followed the measured velocity data when flows were above the top of bank (Figure 6b). Because we could only calibrate the model to a single roughness value, we chose roughness characteristics representative of the flows that were overtopping the floodplain and accepted the larger errors in the channel at low flows since flood flows were of most interest in this study. The two floodplain velocity locations show that the models were not consistent among each other and not consistent for the floodplain locations. For the upstream floodplain location, the only model that somewhat followed the measured velocity data was the DLS pixel method, whereas all the other methods underestimated the depth-average velocity (Figure 6a). For the downstream floodplain location, the reach method and the two patch methods slightly overestimated the measured velocity data, whereas the pixel methods substantially overestimated the measured velocity data (Figure 6c). These stark differences among the models and between the floodplain sensors were due to the large differences in roughness values assigned for the same locations, which are denoted for each model in the legend of Figure 6.

For the validation results, we found no significant differences $(p>0.05)$ when comparing the WSEs from the seventeen wells (Figure 1a) during the seven flood events to the modeled WSEs (Figure 7). All modeled values are strongly correlated, with $r^{2}$ values between 0.93 and 0.94 . The DLS pixel method predicted the WSEs better than the calibrated models (DLS patch and reach). The pixel methods resulted in the smallest RMSE (SfM: $0.136 \mathrm{~m}$, DLS: $0.124 \mathrm{~m}$ ), by $0.02 \mathrm{~m}$, suggesting that the empirical equations slightly outperform the patch and reach methods, which assigns roughness values based solely on height. Models with DLS data also had lower WSE RMSEs, by $0.01 \mathrm{~m}$, when compared to models utilizing SfM. 


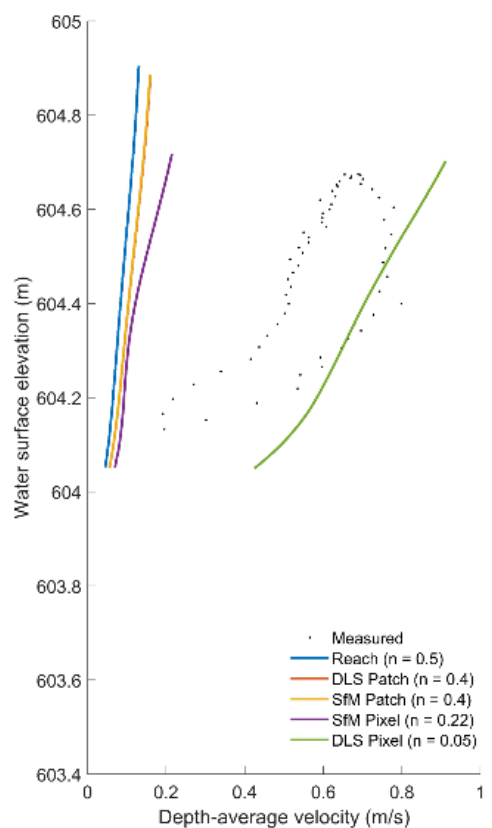

(a)

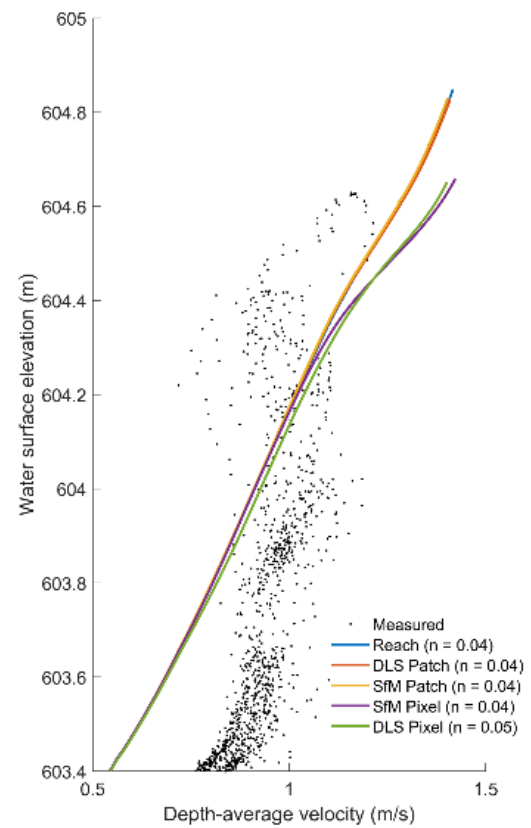

(b)

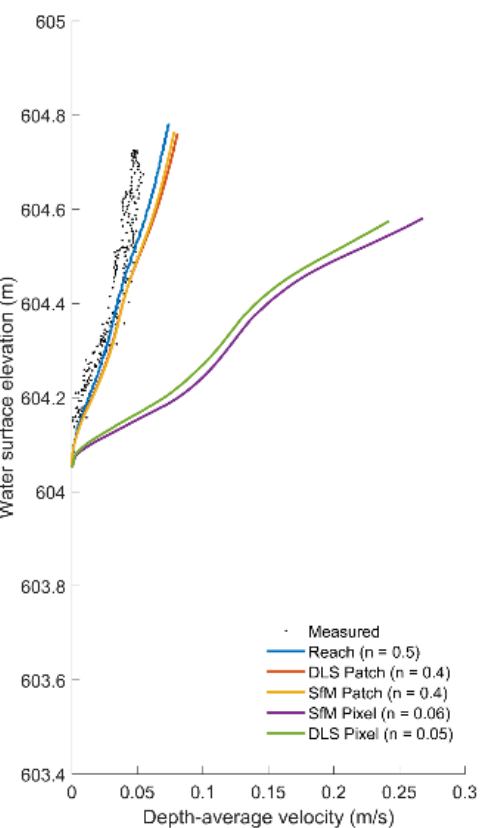

(c)

Figure 6. Velocity sensor data compared to modeled velocities and WSE with roughness values of each velocity sensor location denoted: (a) data taken from upstream floodplain at an elevation of $603.412 \mathrm{~m}$, (b) Data taken from channel bed at an elevation of $602.949 \mathrm{~m}$, (c) Data taken from downstream floodplain at an elevation of $603.825 \mathrm{~m}$.

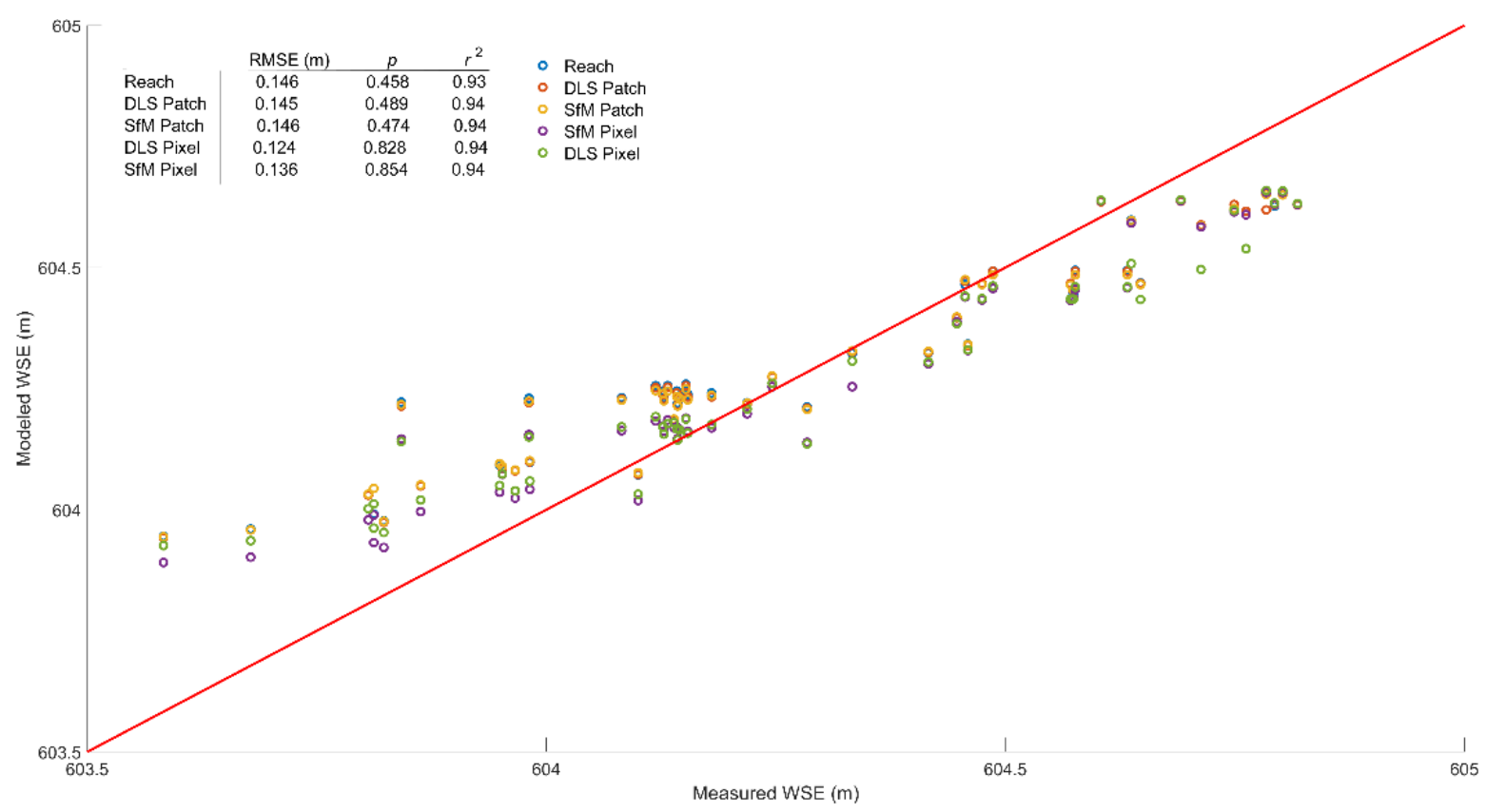

Figure 7. Comparison of measured groundwater well WSE to simulated WSE from the 23 September 2018, 11 October 2018 and 31 October 2019 floods. The RMSEs, $p$-values and $r^{2}$ values are from the validation step. The $p$-values are outputs of the Wilcoxon Rank-Sum Test.

From the models, flood extents for each roughness raster were compared to the manually flagged flood extent with a stream stage at Bridge 2 (Figure 2) of approximately $1.53 \mathrm{~m}$ (606.56 $\mathrm{m}$ in elevation) (Figure 8). Only the reach method and one of each of the other methods are shown in Figure 8 because there was little difference between the DLS and SfM models. The patch method estimated the flood extents most accurately with slight deviation farthest downstream (Figure 8a). The DLS pixel method (Figure 8b) tended to 
underestimate the flood, as seen in the top right corner of flood extent. The reach method (Figure 8c) tended to overestimate the flood, as seen in the top right corner and bottom left corner of the flood extent. Holistically, the models overestimated when compared to WSEs at the flagged flood extents, especially farther downstream (Figure 9). The reach method overestimated the most with the patch method not far behind.

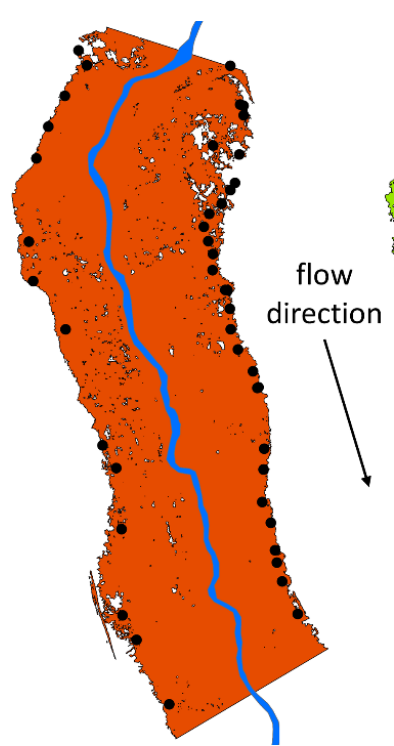

(a)

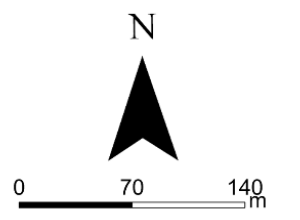

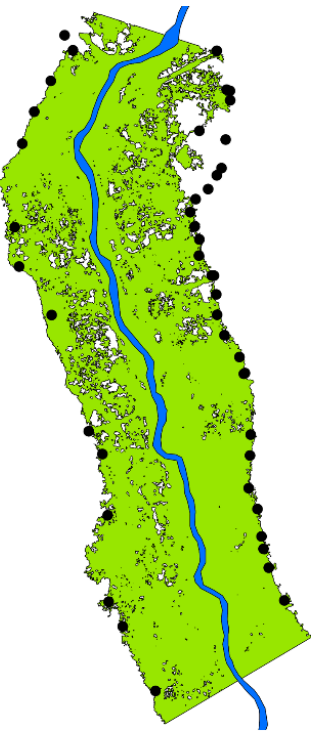

(b)

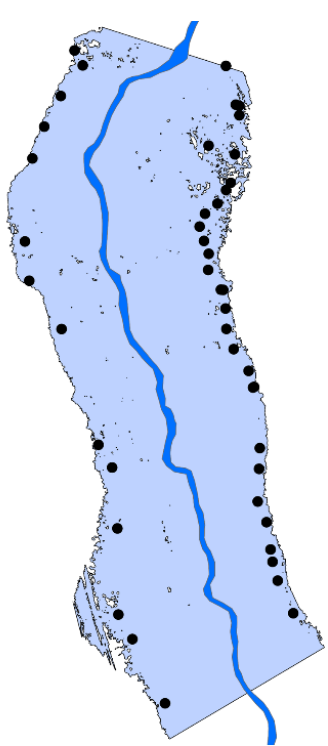

(c)
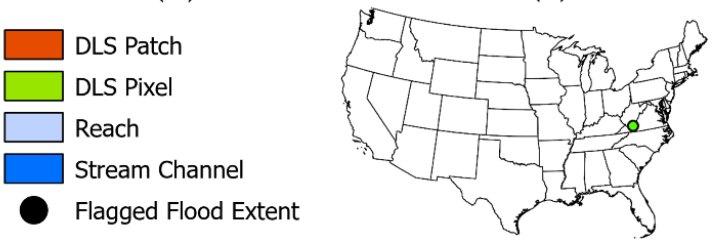

Figure 8. Flagged flood extent on 11 October 2018 compared to modeled flood extents from: (a) DLS patch, (b) DLS pixel, and (c) reach methods. The results using the SfM patch and pixel methods are not shown since there was little difference between the DLS and SfM models.

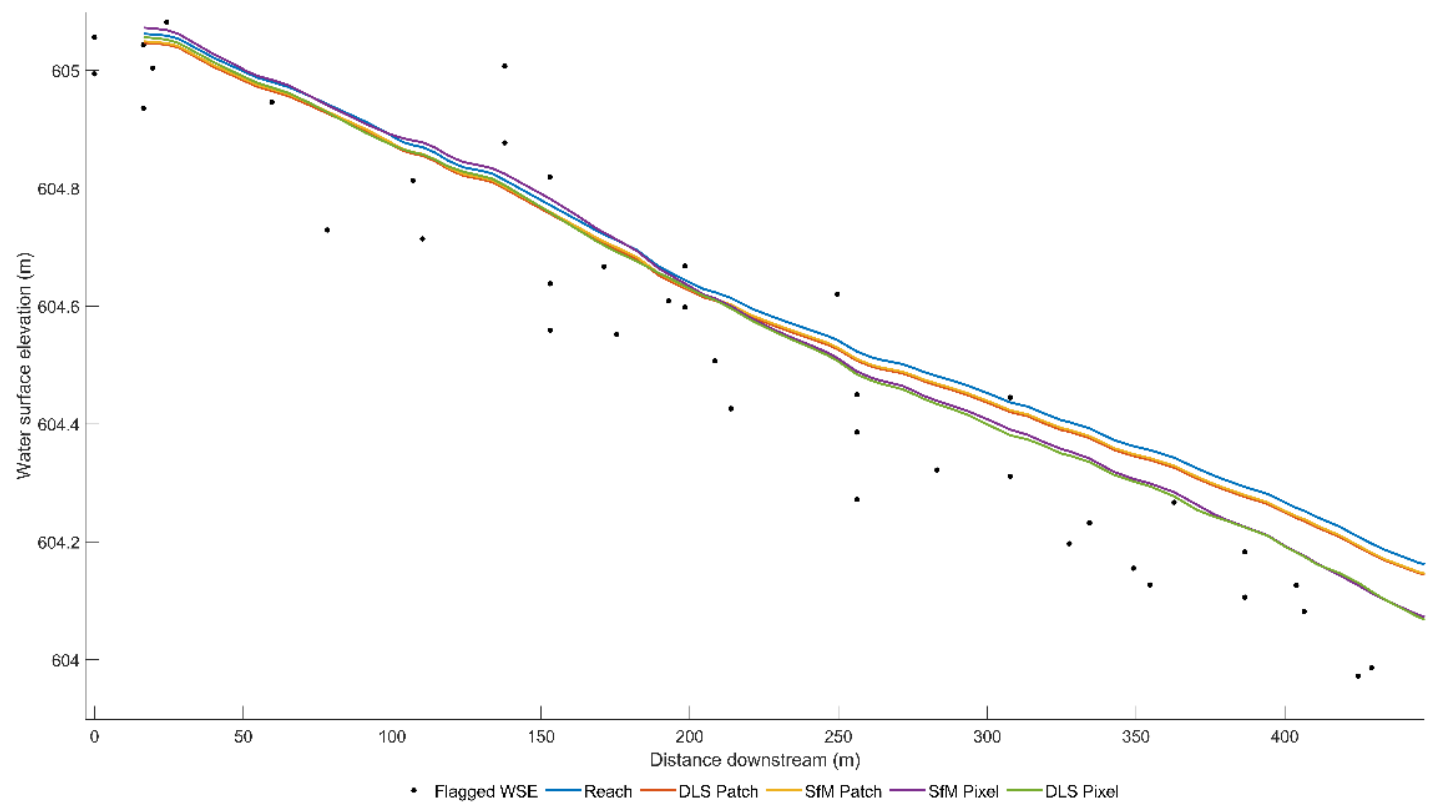

Figure 9. WSE at the flagged flood extents on 11 October 2018 compared to modeled values. 


\section{Discussion}

\subsection{Discussion of Results}

Evaluation of WSEs at the flagged flood extents showed discrepancies at the downstream end of our study reach (Figures 8 and 9 ). These may be attributed to model boundary condition issues or the presence of denser vegetation along this portion of the floodplain. However, we suspect that this most likely occurred due to consistently denser vegetation occurring downstream of Bridge 2, and because no velocity sensor was placed in this section, effectively allowing the calibrated methods to be biased to the conditions in the middle of the reach where calibration data were measured. Additionally, flagging flood extents can be difficult due to difficulties seeing the floodwaters in areas with thick vegetation. Another limitation to flagging is that it takes time, thus it likely does not capture the true peak of the hydrograph.

The DLS pixel method predicted the WSEs better than the calibrated models (DLS patch and reach). This is an important note because the pixel method does not require a gage to calibrate to, meaning it could be applied to areas without traditional monitoring data and reduces the amount of time running the models for calibration.

All modeled WSEs were not significantly different from the groundwater well WSEs ( $p$-values $>0.05$; Figure 7) with $r^{2}$ values between 0.93 and 0.94 . The resulting $r^{2}$ values are an improvement over ALS studies, such as Cobby et al. [42], who found constant $n$ model runs had $p$-values less than 0.05. This is also an improvement over Abu-Aly et al. [22], another ALS study, who reported an $r^{2}$ of 0.60 . Therefore, utilizing high-resolution DLS data for model inputs, such as the DEM, appears to improve hydrodynamic simulations. Additionally, it can be noted in Figure 7 that lower WSEs are over estimating, while the higher WSEs are underestimating across all models. Again, these differences are attributed to potential boundary condition issues, as well as denser vegetation, namely American Sycamore trees, being present at the downstream portion of our study site.

The SfM pixel method RMSE $(0.136 \mathrm{~m})$ was slightly higher than that reported by Tamminga et al. [43] where they used photogrammetry to create $2 \mathrm{D}$ hydrodynamic model inputs, and reported a RMSE of $0.1325 \mathrm{~m}$. Their study area was for a braided channel, that appeared to have less vegetation in their flow area. Even with this difference, our RMSE closely agrees with theirs, with only a $3.5 \mathrm{~mm}$ difference. One caveat of our data analysis is that the DLS DEM was used for all model runs (even those using SfM roughness estimates) to ensure that the only changing variable in the model is the roughness itself. For more detailed analysis for determining the accuracy of UAV-derived vegetation height, the reader is directed to Kucharczyk et al. [7] for DLS and Dandois and Ellis [34] for SfM photogrammetry.

Both the DLS and SfM roughness raster data layers created by the pixel method had $n$ values ranging from 0.05 to 0.92 (Figure $4 \mathrm{f}, \mathrm{g}$ ). Most values were 0.05 , for very short $(<0.1 \mathrm{~m})$ vegetation in the floodplain. These values are consistent with the findings of Mason et al. [27], who reported floodplain $n$ values ranging from 0.07 to 0.83 at high stage (depths around $1 \mathrm{~m}$ in the floodplain). Because the normal depth was set to $1 \mathrm{~m}$, the tall grass around $1 \mathrm{~m}$ had the largest $n$ values. This is also due to the separation in vegetation classes by the two formulas, where $1 \mathrm{~m}$ vegetation heights would have the highest roughness value. Trees receive roughness values in the 0.60 range for the pixel method, which is much higher than lookup table values, which range from 0.03 to 0.20 [16].

\subsection{DEM and Other Considerations}

There are no significant differences between each roughness estimation method (Figures 7-9). Such small differences in the presented statistics and figures are likely attributed to the consistent use of the DLS DEM, which has a resolution of $10 \mathrm{~cm}$, whereas most open access DEMs have larger resolutions ranging from $1 \mathrm{~m}$ to $5 \mathrm{~m}$. Utilization of these open access DEMs could produce different results since they do not account for microtopography as well as our $10 \mathrm{~cm}$ DLS DEM. 
Floodplain vegetation at the StREAM Lab is extremely complex as exhibited by the velocities in Figure 6, therefore, these hydrodynamic simulations are not able to consistently account for velocities at every location, especially along the boundaries between differing vegetation types and heights. They also highlight how each roughness estimation method results in a different roughness value for the same location. The roughness values assigned for the upstream floodplain velocity sensor ranged from 0.05 to 0.5 (Figure 6a), with the DLS pixel method having the lowest $n$ value, but following the measured velocity data values the best. For the downstream floodplain velocity sensor, roughness values had the same range as the upstream floodplain velocity sensor (Figure $6 \mathrm{c}$ ), but the reach and patch methods predicted the measured values the best while having the higher roughness values ( 0.5 to 0.4 compared to 0.06 to 0.05 ).

Determining whether to use lidar or SfM photogrammetry for mapping roughness for flood modeling depends on available resources and research goals. The advantages and disadvantages of each is an active discussion topic especially since there is not complete lidar coverage of the US. Drone lidar systems are very expensive, while statewide photogrammetric point clouds have been collected for certain US states and photogrammetry is a capability of most drones. UAV photogrammetry costs substantially less than UAV DLS (2000 USD versus 150,000 USD for this study), but generally requires a high-resolution DEM for ground detection. Cross sections at the StREAM Lab are shown in Figure 10 for visual comparison of resulting point clouds. The SfM cross sections tend to overestimate heights for most flat grassy surfaces, but are able to capture the general outline of the trees. These results correspond with the findings of Thomas et al. [58] who found high error (RMSE $= \pm 1 \mathrm{~m}$ ) when comparing field and SfM derived grass heights, and Sankey et al. [33], who found strong correlations between SfM derived and field measured tree height. They determined that the relationship was not as good as DLS tree height $\left(r^{2}=0.90\right)$, but that it was highly correlated $\left(r^{2}=0.70\right)$. Another study found a higher correlation between field measured tree height and SfM derived tree height $\left(r^{2}=0.96\right)$ but had a large error value $(R M S E=1.91)$ [59]. These differences shown in Figure 10 and the cited studies might explain some of the starkly different behavior in the modeled velocity data and the flood extent differences. Additionally, the SfM and DLS point clouds were collected in different years (2020 versus 2018) and different seasonal months (June versus October) due to data availability. These time and seasonal differences could also affect the point cloud cross sections, modeled velocity data, and modeled flood extents.

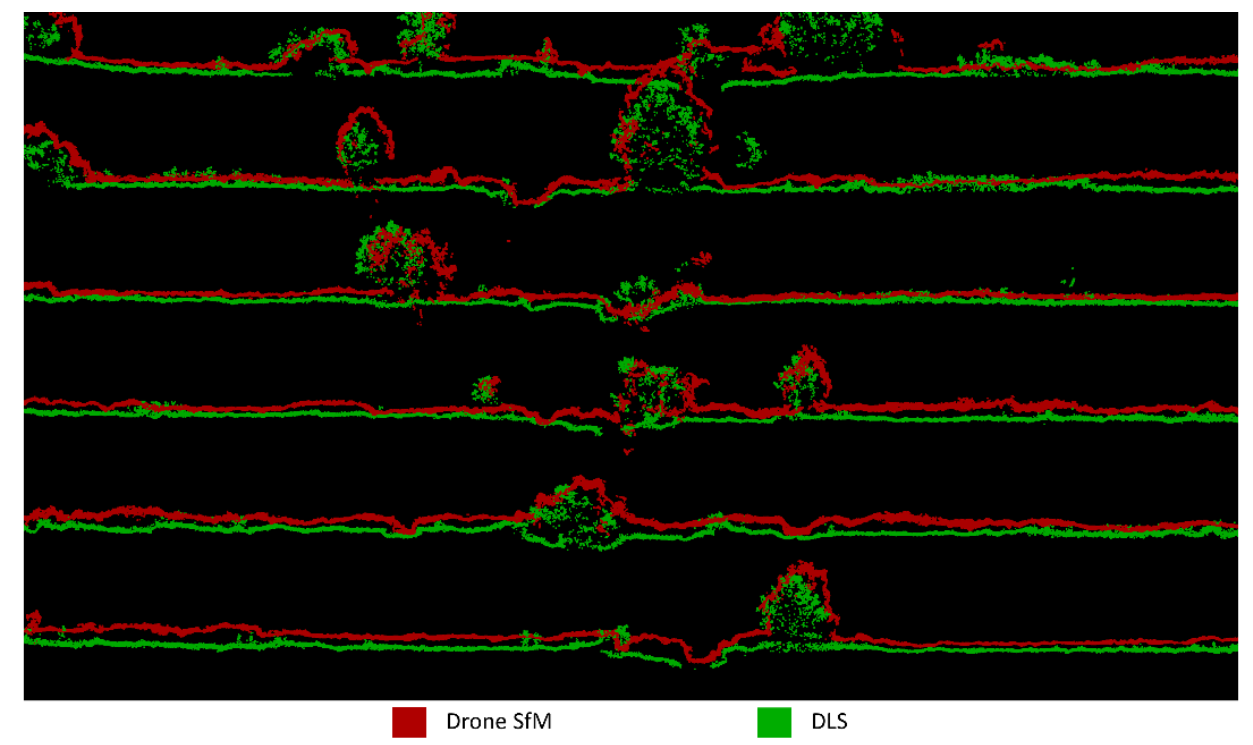

Figure 10. Cross-sections from StREAM Lab showing the differences between SfM and DLS point clouds. 
Another cost to consider is the processing power required to create a dense point cloud using SfM techniques, compared to lidar which computes a raw LAS file with limited processing. The last consideration for SfM is the increased time necessary to fly more than one flight. In this study, we needed four SfM flights, which took around two hours, to get data comparable to the one 30-min DLS flight to cover the same area, though the SfM flights could have been flown at higher altitudes to lessen the flight duration, resulting in slightly lower resolution data. Even with these considerations, SfM is significantly less expensive. There is only a difference of $0.01 \mathrm{~m}$ RMSE between SfM and DLS data from this study, but keep in mind that our study utilized a high-resolution DLS DEM, which represents the ground much more accurately than a SfM DEM. Further studies are needed to determine if SfM derived DEM data can provide adequate results for 2D hydrodynamic modeling.

\subsection{Future Studies}

Future research should utilize freely available DEMs to see how the DEM resolution affects modeled results. Additionally, future research should include more field data that is purposely measured at critical areas such as where vegetation type changes and where inset floodplains are located. Seasonal changes should also be accounted for, namely the die-off of herbaceous vegetation. This could be done by updating the roughness raster data layers with seasonal UAV flights.

Additionally, the downstream discrepancies seen in this study most likely occurred since vegetation in this section of the floodplain is much denser than elsewhere. This shows that classifying vegetation by height alone does not account for differences in density that would increase roughness, thus future research needs to better evaluate vegetation density and not just vegetation height. Other research topics to explore are depth dependent roughness and how roughness might be altered after each flood event. Lidar paired with spectral data could also be used to account for both the structure and function of floodplain vegetation seasonally along with before and after flood events [28].

\section{Conclusions}

DLS and SfM data were collected over the Virginia Tech StREAM Lab in Blacksburg, Virginia, US. The DLS point cloud was used to create a DEM. The DEM was then subtracted from each point cloud to determine vegetation height. To create a raster data layer of vegetative roughness, three different roughness estimation techniques were implemented. For the first method, known as the "reach" method, a uniform roughness was calibrated for the entire reach, one value for the channel and one value for the floodplain. An in-channel velocity sensor was used to calibrate the channel roughness and the floodplain velocity sensor was used to calibrate the floodplain roughness with final values being 0.04 and 0.5 , respectively. For the second method, known as the "patch" method, roughness values corresponding to classes of floodplain vegetation were assigned based on the CHM. As in the previous method, these vegetation class roughness values were then calibrated by using velocity sensors: grass ( $0 \mathrm{~m}$ to $1 \mathrm{~m}, n=0.05)$, scrub ( $1 \mathrm{~m}$ to $2.5 \mathrm{~m}, n=0.07)$, small tree ( $2.5 \mathrm{~m}$ to $5 \mathrm{~m}, n=0.16$ ) and large tree ( $5 \mathrm{~m}$ to $20 \mathrm{~m}, n=0.20)$. The third method, known as the "pixel" method, assigned a roughness value for each pixel using a set of equations that considers if the vegetation is short submerged vegetation less than $1 \mathrm{~m}$ or non-submerged medium to tall vegetation along with elasticity. The pixel and patch methods were applied to each CHM. Then, each raster was used for hydrodynamic modeling in 2D HEC-RAS. Field data were then used to calibrate (velocity sensors), validate (groundwater well WSEs), and compare (flood extents) the roughness methods derived from SfM and DLS datasets.

For the flood extents, the reach method tended to overestimate while the pixel method tended to underestimate. There were no visual differences between DLS and SfM within the pixel and patch methods. For the groundwater well WSEs, there were no significant differences between the measured and modeled results and no significant differences between the modeled results. The pixel methods had the smallest RMSE (SfM: $0.136 \mathrm{~m}$, DLS: $0.124 \mathrm{~m}$ ), showing that the empirical equations slightly outperform the patch method, 
which assigned roughness values solely based on height. All the calculated statistics were relatively similar, probably due to the consistent use of the high-resolution DEM derived from the DLS point cloud. Research utilizing freely accessible DEMs should be performed to investigate how DEM resolution affects hydrodynamic modeling results. Future research should utilize point clouds to investigate vegetation density, how vegetation affects depthdependent roughness, how seasonal vegetation changes affect flooding, and how individual flood events may alter vegetation roughness.

Author Contributions: Conceptualization, J.A.C. and W.C.H.; methodology, C.A.A., J.A.C., T.J.P. and W.C.H.; validation, C.A.A., E.M.P. and J.A.C.; formal analysis, C.A.A., E.M.P. and J.A.C.; resources, J.A.C. and W.C.H.; data curation, T.J.P., C.A.A., E.M.P. and J.A.C.; writing-original draft preparation, C.A.A., E.M.P.; writing-review and editing, E.M.P., T.J.P., J.A.C., W.C.H., C.A.A.; visualization, C.A.A. and E.M.P.; supervision, J.A.C., T.J.P. and W.C.H.; project administration, J.A.C., T.J.P. and W.C.H.; funding acquisition, J.A.C. and W.C.H. All authors have read and agreed to the published version of the manuscript.

Funding: This work was supported by the Virginia Agricultural Experiment Station (Blacksburg), the USDA National Institute of Food and Agriculture, U.S. Department of Agriculture (Washington, DC, USA) and the Virginia Tech Interdisciplinary Graduate Education Program in Remote Sensing. We would also like to thank the Virginia Tech Open Access Subvention Fund for partially funding this paper.

Acknowledgments: We would like to acknowledge support from undergraduates, Alexa Reed and Thomas Schubert along with support from StREAM Lab Manager and drone pilot, Laura Lehmann.

Conflicts of Interest: The authors declare no conflict of interest.

\section{References}

1. Fausch, K.D.; Torgersen, C.E.; Baxter, C.V.; Li, H.W. Landscapes to Riverscapes: Bridging the Gap between Research and Conservation of Stream Fishes: A Continuous View of the River Is Needed to Understand How Processes Interacting among Scales Set the Context for Stream Fishes and Their Habitat. BioScience 2002, 52, 483-498. [CrossRef]

2. Allan, J.D. Landscapes and Riverscapes: The Influence of Land Use on Stream Ecosystems. Annu. Rev. Ecol. Evol. Syst. 2004, 35, 257-284. [CrossRef]

3. Tomsett, C.; Leyland, J. Remote sensing of river corridors: A review of current trends and future directions. River Res. Appl. 2019, 35, 779-803. [CrossRef]

4. Groisman, P.; Knight, R.W.; Karl, T.R. Heavy Precipitation and High Streamflow in the Contiguous United States: Trends in the Twentieth Century. Bull. Am. Meteorol. Soc. 2001, 82, 219-246. [CrossRef]

5. Hirabayashi, Y.; Mahendran, R.; Koirala, S.; Konoshima, L.; Yamazaki, D.; Watanabe, S.; Kim, H.; Kanae, S. Global flood risk under climate change. Nat. Clim. Chang. 2013, 3, 816-821. [CrossRef]

6. Carbonneau, P.; Fonstad, M.; Marcus, W.A.; Dugdale, S. Making riverscapes real. Geomorphology 2012, 137, 74-86. [CrossRef]

7. Kucharczyk, M.; Hugenholtz, C.H.; Zou, X. UAV-LiDAR accuracy in vegetated terrain. J. Unmanned Veh. Syst. 2018, 6, 212-234. [CrossRef]

8. Resop, J.P.; Lehmann, L.; Hession, W.C. Drone Laser Scanning for Modeling Riverscape Topography and Vegetation: Com-parison with Traditional Aerial Lidar. Drones 2019, 3, 35. [CrossRef]

9. Woodget, A.S.; Austrums, R.; Maddock, I.; Habit, E. Drones and digital photogrammetry: From classifications to continuums for monitoring river habitat and hydromorphology. Wiley Interdiscip. Rev. Water 2017, 4, e1222. [CrossRef]

10. Brignoli, L.; Annable, W.K.; Plumb, B.D. Assessing the accuracy of vegetative roughness estimates using unmanned aerial vehicles [UAVs]. Ecol. Eng. 2018, 118, 73-83. [CrossRef]

11. Marteau, B.; Vericat, D.; Gibbins, C.; Batalla, R.; Green, D.R. Application of Structure-from-Motion photogrammetry to river restoration. Earth Surf. Process. Landf. 2017, 42, 503-515. [CrossRef]

12. Arcement, G.J.; Schneider, V.R. Guide for Selecting Manning's Roughness Coefficients for Natural Channels and Flood Plains; US Geological Survey: Denver, CO, USA, 1989. [CrossRef]

13. Curran, J.C.; Hession, W.C. Vegetative impacts on hydraulics and sediment processes across the fluvial system. J. Hydrol. 2013, 505, 364-376. [CrossRef]

14. Manning, R. On the Flow of Water in Open Channels and Pipes. Available online: http://sources.nli.ie/Record/PS_UR_067903 (accessed on 30 June 2021).

15. Keys, T.A.; Jones, C.N.; Scott, D.T.; Chuquin, D. A cost-effective image processing approach for analyzing the ecohydrology of river corridors. Limnol. Oceanogr. Methods 2016, 14, 359-369. [CrossRef]

16. Chow, V. Open-Channel Hydraulics; McGraw-Hill Book Company: New York, NY, USA, 1959; ISBN 978-0-07-010776-2. 
17. Barnes, H. Roughness Characteristics of Natural Channels; USGS Water Supply Paper; US Government Printing Office: Washington, DC, USA, 1969; Volume 7, p. 354.

18. Cowan, W.L. Estimating Hydraulic Roughness Coefficients. Agric. Eng. 1956, 337, 470-500.

19. Green, J.C. Modelling flow resistance in vegetated streams: Review and development of new theory. Hydrol. Process. 2005, 19, 1245-1259. [CrossRef]

20. Wang, J.; Zhang, Z. Evaluating Riparian Vegetation Roughness Computation Methods Integrated within HEC-RAS. J. Hydraul. Eng. 2019, 145, 04019020. [CrossRef]

21. Corenblit, D.; Tabacchi, E.; Steiger, J.; Gurnell, A.M. Reciprocal interactions and adjustments between fluvial landforms and vegetation dynamics in river corridors: A review of complementary approaches. Earth Sci. Rev. 2007, 84, 56-86. [CrossRef]

22. Abu-Aly, T.; Pasternack, G.; Wyrick, J.; Barker, R.; Massa, D.; Johnson, T. Effects of LiDAR-derived, spatially distributed vegetation roughness on two-dimensional hydraulics in a gravel-cobble river at flows of 0.2 to 20 times bankfull. Geomorphology 2014, 206, 468-482. [CrossRef]

23. Nepf, H.M. Drag, turbulence, and diffusion in flow through emergent vegetation. Water Resour. Res. 1999, 35, 479-489. [CrossRef]

24. Kouwen, N.; Unny, T.E. Flexible Roughness in Open Channels. J. Hydraul. Div. 1973, 99, 713-728. [CrossRef]

25. Kouwen, N.; Li, R.-M. Biomechanics of Vegetative Channel Linings. J. Hydraul. Div. 1980, 106, 1085-1103. [CrossRef]

26. Fathi-Maghadam, M.; Kouwen, N. Nonrigid, Nonsubmerged, Vegetative Roughness on Floodplains. J. Hydraul. Eng. 1997, 123, 51-57. [CrossRef]

27. Mason, D.C.; Cobby, D.M.; Horritt, M.S.; Bates, P.D. Floodplain friction parameterization in two-dimensional river flood models using vegetation heights derived from airborne scanning laser altimetry. Hydrol. Process. 2003, 17, 1711-1732. [CrossRef]

28. Straatsma, M.; Baptist, M. Floodplain roughness parameterization using airborne laser scanning and spectral remote sensing. Remote Sens. Environ. 2008, 112, 1062-1080. [CrossRef]

29. Popescu, S.C.; Wynne, R.H.; Nelson, R.F. Estimating plot-level tree heights with lidar: Local filtering with a canopy-height based variable window size. Comput. Electron. Agric. 2002, 37, 71-95. [CrossRef]

30. Merwade, V.; Cook, A.; Coonrod, J. GIS techniques for creating river terrain models for hydrodynamic modeling and flood inundation mapping. Environ. Model. Softw. 2008, 23, 1300-1311. [CrossRef]

31. Straatsma, M. Quantitative Mapping of Hydrodynamic Vegetation Density of Floodplain Forests Under Leaf-off Conditions Using Airborne Laser Scanning. Photogramm. Eng. Remote Sens. 2008, 74, 987-998. [CrossRef]

32. Tompalski, P.; Coops, N.C.; White, J.; Wulder, M.A.; Yuill, A. Characterizing streams and riparian areas with airborne laser scanning data. Remote Sens. Environ. 2017, 192, 73-86. [CrossRef]

33. Sankey, T.; Donager, J.; McVay, J.; Sankey, J.B. UAV lidar and hyperspectral fusion for forest monitoring in the southwestern USA. Remote Sens. Environ. 2017, 195, 30-43. [CrossRef]

34. Dandois, J.P.; Ellis, E.C. High spatial resolution three-dimensional mapping of vegetation spectral dynamics using computer vision. Remote Sens. Environ. 2013, 136, 259-276. [CrossRef]

35. Hugenholtz, C.H.; Whitehead, K.; Brown, O.W.; Barchyn, T.E.; Moorman, B.; LeClair, A.; Riddell, K.; Hamilton, T. Geomorphological mapping with a small unmanned aircraft system (sUAS): Feature detection and accuracy assessment of a photogrammetrically-derived digital terrain model. Geomorphology 2013, 194, 16-24. [CrossRef]

36. Dietrich, J.T. Riverscape mapping with helicopter-based Structure-from-Motion photogrammetry. Geomorphology 2016, 252, 144-157. [CrossRef]

37. Cruzan, M.B.; Weinstein, B.G.; Grasty, M.R.; Kohrn, B.F.; Hendrickson, E.C.; Arredondo, T.M.; Thompson, P.G. Small Unmanned Aerial Vehicles (Micro-Uavs, Drones) in Plant Ecology. Appl. Plant. Sci. 2016, 4, 1600041. [CrossRef]

38. Rusnák, M.; Sládek, J.; Kidová, A.; Lehotský, M. Template for high-resolution river landscape mapping using UAV technology. Meas. J. Int. Meas. Confed. 2018, 115, 139-151. [CrossRef]

39. Langhammer, J. UAV Monitoring of Stream Restorations. Hydrology 2019, 6, 29. [CrossRef]

40. Westoby, M.J.; Brasington, J.; Glasser, N.F.; Hambrey, M.J.; Reynolds, J.M. Structure-from-Motion photogrammetry: A low-cost, effective tool for geoscience applications. Geomorphology 2012, 179, 300-314. [CrossRef]

41. Stott, E.; Williams, R.D.; Hoey, T.B. Ground Control Point Distribution for Accurate Kilometre-Scale Topographic Mapping Using an RTK-GNSS Unmanned Aerial Vehicle and SfM Photogrammetry. Drones 2020, 4, 55. [CrossRef]

42. Cobby, D.M.; Mason, D.C.; Horritt, M.S.; Bates, P.D. Two-dimensional hydraulic flood modelling using a finite-element mesh decomposed according to vegetation and topographic features derived from airborne scanning laser altimetry. Hydrol. Process. 2003, 17, 1979-2000. [CrossRef]

43. Tamminga, A.; Hugenholtz, C.; Eaton, B.; Lapointe, M. Hyperspatial Remote Sensing of Channel Reach Morphology and Hydraulic Fish Habitat Using an Unmanned Aerial Vehicle (UAV): A First Assessment in the Context of River Research and Management. River Res. Appl. 2014, 31, 379-391. [CrossRef]

44. Ballesteros, J.; Bodoque, J.; Díez-Herrero, A.; Sanchez-Silva, M.; Stoffel, M. Calibration of floodplain roughness and estimation of flood discharge based on tree-ring evidence and hydraulic modelling. J. Hydrol. 2011, 403, 103-115. [CrossRef]

45. Schwartz, J.S. Use of a 2D Hydrodynamic Model for Stream Restoration Design of High-flow Habitat in Low-gradient Midwest Streams. Prot. Restor. Urban Rural Streams 2004, 242-251. [CrossRef]

46. Brunner, G.W. HEC-RAS, River Analysis System Users Manual; USACE Hydraulic Engineering Center: Davis, CA, USA, 2016; pp. 1-171. 
47. Wynn Thompson, T.; Cully Hession, W.; Durelle, S. Resource Magazine; ASABE: St. Joseph, MI, USA, 2012; pp. 8-9.

48. Ries, K.G.; Newson, J.K.; Smith, M.J.; Guthrie, J.D.; Steeves, P.A.; Haluska, T.L.; Kolb, K.R.; Thompson, R.F.; Santoro, R.D.; Vraga, H.W. StreamStats; Version 4; Fact Sheet: Reston, VA, USA, 2017.

49. Benham, B.; Brannan, K.; Dillaha, T.; Mostaghimi, S.; Wagner, R.; Wynn, J.; Yagow, G.; Zeckoski, R. Benthic TMDL for Stroubles Creek in Montgomery County, Virginia; Virginia Departments of Environmental Quality and Conservation and Recreation: Richmond, VA, USA, 2003; pp. 1-83.

50. Wynn, T.; Hession, W.C.; Yagow, G. Stroubles Creek Stream Restoration, Final Project Report; Virginia Department of Conservation and Recreation: Richmond, VA, USA, 2010; pp. 1-19.

51. Azinheira, D.L.; Scott, D.T.; Hession, W.; Hester, E.T. Comparison of effects of inset floodplains and hyporheic exchange induced by in-stream structures on solute retention. Water Resour. Res. 2014, 50, 6168-6190. [CrossRef]

52. Keulegan, G.H. Laws of turbulent flow in open channels. J. Res. Natl. Inst. Stand. Technol. 1938, 21, 707. [CrossRef]

53. Garcia, M. Chapter 2 Sediment Transport and Morphodynamics. In Sedimentation Engineering: Processes, Measurements, Modeling, and Practice; American Society of Civil Engineers: Reston, VA, USA, 2008; ISBN 0-7844-0814-9.

54. Carbonneau, P.E.; Dietrich, J.T. Cost-effective non-metric photogrammetry from consumer-grade sUAS: Implications for direct georeferencing of structure from motion photogrammetry. Earth Surf. Process. Landf. 2016, 42, 473-486. [CrossRef]

55. Fonstad, M.A.; Dietrich, J.; Courville, B.C.; Jensen, J.L.; Carbonneau, P.E. Topographic structure from motion: A new development in photogrammetric measurement. Earth Surf. Process. Landf. 2013, 38, 421-430. [CrossRef]

56. Hopkinson, C.; Chasmer, L.E.; Sass, G.; Creed, I.F.; Sitar, M.; Kalbfleisch, W.; Treitz, P. Vegetation class dependent errors in lidar ground elevation and canopy height estimates in a boreal wetland environment. Can. J. Remote Sens. 2005, 31, 191-206. [CrossRef]

57. Kouwen, N. Field estimation of the biomechanical properties of grass. J. Hydraul. Res. 1988, 26, 559-568. [CrossRef]

58. Thomas, A.F.; Frazier, A.E.; Mathews, A.J.; Cordova, C.E. Impacts of Abrupt Terrain Changes and Grass Cover on Vertical Accuracy of UAS-SfM Derived Elevation Models. Pap. Appl. Geogr. 2020, 6, 1-16. [CrossRef]

59. Isibue, E.W.; Pingel, T.J. Unmanned aerial vehicle based measurement of urban forests. Urban. For. Urban. Green. 2020, $48,126574$. [CrossRef] 